
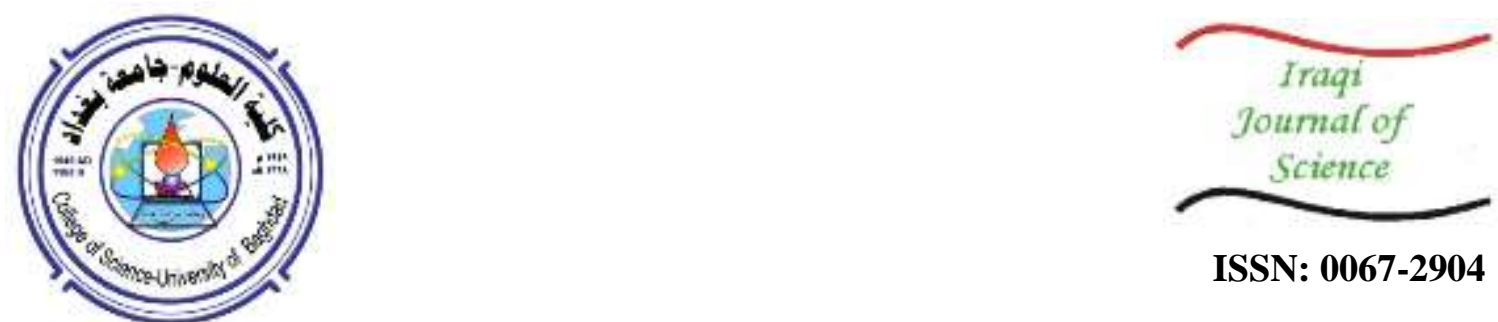

ISSN: 0067-2904

\title{
Bulk Volume Determination by Modified Water Displacement Method
}

\author{
Ubong Williams Robert ${ }^{1}$, Sunday Edet Etuk ${ }^{2}$, Okechukwu Ebuka Agbasi ${ }^{3 *}$ \\ ${ }^{1}$ Department of Physics, Akwa Ibom State University, Ikot Akpaden, Mkpat Enin \\ ${ }^{2}$ Department of Physics, University of Uyo, Uyo \\ ${ }^{3}$ Department of Physics, Michael Okpara University of Agriculture, Umudike
}

\begin{abstract}
In this work, a modified water displacement method (MWDM) was designed and used alongside geometry method (GEM), overflow method (OFM) and water displacement method (WDM) for determination of bulk volume of a porous solid. Their results were analyzed graphically and statistically. On testing against the data obtained by Suspension/Buoyancy Method (SBM) used as gold standard, it was found that only those generated by the modified water displacement method (MWDM) were of very high accuracy and precision. Apart from its reproducibility being within the recommended range for acceptability of a test method, the technique is cost-effective and easy to apply even with an ungraduated glass cylindrical tube. This can go a long way in enhancing thorough physical characterization of porous solids without the use of high cost, sophisticated and complex equipment.
\end{abstract}

Keywords: Reproducibility, Ungraduated Cylindrical Tube, Bland-Atman Plot, Composite Board.

\section{Introduction}

In everyday life, the emerging properties exhibited by fabricated porous materials are of enormous practical importance. As a result, there has been a pronounced increase in the range of applications of such materials from applied science to medical diagnosis and engineering. Examples of such applications include but not limited to those reported by [1, 2, 3]. In all cases of applications, the selection of suitable porous materials is only possible through proper characterization, without which no scientific understanding of their properties could be ascertained. It is a considered fact that volume remains a very vital parameter to be determined in probing the properties of porous materials. This is because it affects density which in turn plays a major role in the development of new materials and helps to address their functionality.

Though no measurement can be made with total accuracy, it is however, understood that the level of achievable accuracy can be improved based on certain approaches one adopts in any measurement process. In the laboratory, there are some manual methods often used for determination of bulk volume in order to compute bulk density of a porous solid. For example, the use of geometry method involves measurement of the needed dimensions of a porous solid and application of a suitable mensuration formula to calculate its bulk volume. The formula to be applied, as stated in several textbooks including $[4,5]$ as well as mathematical tables, depends on the shape of the solid in question. Though this is a quick method which can be used only if the porous solid has a regular shape, the results obtained may be of low accuracy due to the surface irregularities that characterize such solid.

Another commonly used method is the water displacement technique. In its present application, a porous solid is made to submerge in the water contained in a graduated measuring cylinder. The bulk volume of the solid is then obtained as the difference between the volume of water before and the one after the immersion [6]. Since a non-wetting liquid like mercury is very expensive, the only cheap way

*Email: agbasi.okechukwu@gmail.com 
of overcoming the adverse effect of water on the porous solid is by coating the solid with waterresistant material before submerging it in the water. But even at that, if the centre of the meniscus of water is not aligned with a premarked graduation on the cylinder, the final volume is only by estimation [7]. As such, the results cannot have high accuracy.

Again, the use of overflow method is also common in laboratories. By this technique, a porous solid is placed in a container of water that has a downward-pointing spout projecting from the side and the water that overflows is collected with a graduated cylinder. As described by [8], the measured volume of the water collected is same as that of the solid submerged. Notably, the results may not be of high accuracy for the same reason stated in the case of water displacement method above. There is also likelihood that the results will vary if the bulk volume of the solid is rather determined from the ratio of the mass of water collected to its density. This later approach requires one to know the water temperature and use the corresponding water density value at that measurement instant.

In addition, method of suspension (also known as Buoyancy technique) is equally a common technique used in laboratories. This method involves determining the mass of a porous solid in air by means of spring balance and also when the solid is fully immersed in water. Then the ratio of the loss in mass (weight in grammes) to the density of water at that temperature is taken to be the bulk volume of the porous solid immersed in the water. Though the attack of water on the solid can be avoided by coating as earlier mentioned, the results obtained can be of very high accuracy only if the spring balance used is digital. This is because digital measuring instruments have higher resolution and greater accuracy than their analog counterparts [9]. Unlike in the cases of vernier calipers and micrometer screw gauges, the type of spring balance commonly found in schools and laboratories is analog. Due to its potential lack of accuracy as a result of its tendency to relax over time, it is difficult to get a very precise reading from it. Hence, estimates of weight (in grammes) are being used where the pointer does not settle at exact mark.

Over the years, it has been observed that the measurement of the bulk volume of porous solids can be of very high accuracy only when sophisticated and advanced instruments are used. But such practice has been suffering major setbacks in many schools and laboratories due to inavailability of such instruments as a result of cost implication. In this work, a modified water displacement technique has been designed to overcome such challenge by using common laboratory materials to determine bulk volume of porous solids with accuracy very close to the one that can be achieved with costly and sophisticated equipment. Specifically, the suspension method employing digital spring balance will be used as "gold standard". Also, the mean values of bulk volume obtained by other methods discussed in this work will be compared with the ones obtained by this standard in order to establish data quality and test effectiveness of the new technique.

\section{Theory of the Modified Water Displacement Technique}

Unlike solids, a liquid substance always takes the shape of its container. According to Archimedes' principle, the volume of fluid displaced when an object is immersed in it is equal to that of the object [10]. By implication, when a solid is completely immersed in water contained in a cylindrical tube, the shape of the displaced water is cylindrical and its volume is same as that of the solid.

In mathematical form, the volume $V_{c}$ of a cylinder can be expressed thus

$V_{c}=\frac{\pi d^{2} h}{4}$

where $\mathrm{d}$ is the internal diameter and $\mathrm{h}$ is the height of interest of the cylinder. It, therefore, follows that if a complete immersion of a solid causes water in a cylindrical tube of external diameter, D and uniform thickness, t to be displaced through a height, $\mathrm{X}$, then the volume, $V_{m}$ of the solid can be determined using

$V_{m}=\frac{\pi(D-2 t)^{2} X}{4}$

For a porous solid of mass, $\mathrm{M}$, surface-sealed by coating with a water-resistant material of density $\rho_{s}$, the volume $V_{s}$, of the coating material is such that

$V_{s}=\frac{(W-M)}{\rho_{s}}$ 
where $\mathrm{W}$ is the mass of the porous solid with the coating on it.

In this case, equations (2) and (3) can be used to determine the bulk volume, V of the porous solid as

$$
V=V_{m}-V_{s}
$$

Hence, if need be, the corresponding bulk density, $\rho$ can be computed according to the relation

$$
\rho=\frac{M}{V}
$$

\section{Experimental Details}

\subsection{Materials and method}

In this work, the porous material used was a composite board prepared by mixing archi sawdust, Plaster of Paris (P.O.P) and water in the ratio of 1:5.6:3.4 by weight and then allowing it to dry completely. The board was cut into ten different sizes of rectangular shape of common thickness and then labelled as samples S1 to S10 for the purpose of easy identification. With the aid of analytical balance (METTLER TOLEDO PL 203, $\mathrm{d}=0.001 \mathrm{~g}$ ), the mass of each sample was measured while the dimensions for computation of bulk volume by geometry method were measured using digital vernier calipers. Measurement of the dimensions was repeated in random manner and the mean bulk volume of each sample was calculated. Thenafter, each sample was surface-coated by dipping in melted waste candle wax (measured density $=0.914 \mathrm{gcm}-3$ ). The masses of the samples after coating were determined orderly and then at random after which the volume of the coating material on each of them was calculated for the two trial runs using equation 3. The temperature of water to be used was measured with digital thermometer (Model No. 305) using K-type immersion probe and the water density value provided by [11] at that temperature $(28 \mathrm{oC})$ was noted. For overflow method, eureka was used and the volume of the coated sample was obtained as the ratio of mass of the water collected to its density. In the case of water displacement method, the volume of each sample was determined as the difference in water volumes in a $100 \mathrm{~cm} 3$ graduated cylinder with estimated accuracy of $0.3 \mathrm{~cm} 3$ observed before and after complete immersion of the sample. For the suspension method, a digital spring scale (ELECTROSAMSON) was used and the volume of each coated sample was obtained as the ratio of the apparent loss in weight (in grammes) of the sample to the water density value. For each of the three methods, two trial runs were performed and the mean volume value was recorded. In the case of the modified water displacement method, an ungraduated glass cylindrical tube of uniform thickness sealed at one end was clamped vertically and filled with water to a reasonable level marked with a tape. The sample was then completely immersed in the water with great care to ensure that the water did not splash on to the inside walls of the tube. A mark was made with tape at the new meniscus level of the water and the displacement of the water was measured with metre rule (since metre rule has a reasonably small reading error being $0.05 \mathrm{~cm}$ ). The external diameter and thickness of the tube were measured with digital vernier calipers and digital micrometer screw gauge respectively. This similar measurement process was repeated on a different day for reproducibility test and on those days, two trial runs were performed, first orderly and then, at random. Also, for each trial run, the volume of the coated sample was calculated using equation 2 . For all the methods involving the use of the coated samples, the bulk volume values of the samples were computed using equation 4 . The mean data obtained were tabulated and analyzed to assess the data quality of the new method proposed in this work. 
3.2 Results

Table 1-Values of parameters in relation to the use of MWDM (with $D=2.986 \mathrm{~cm}$ and $\mathrm{t}=0.156 \mathrm{~cm}$ )

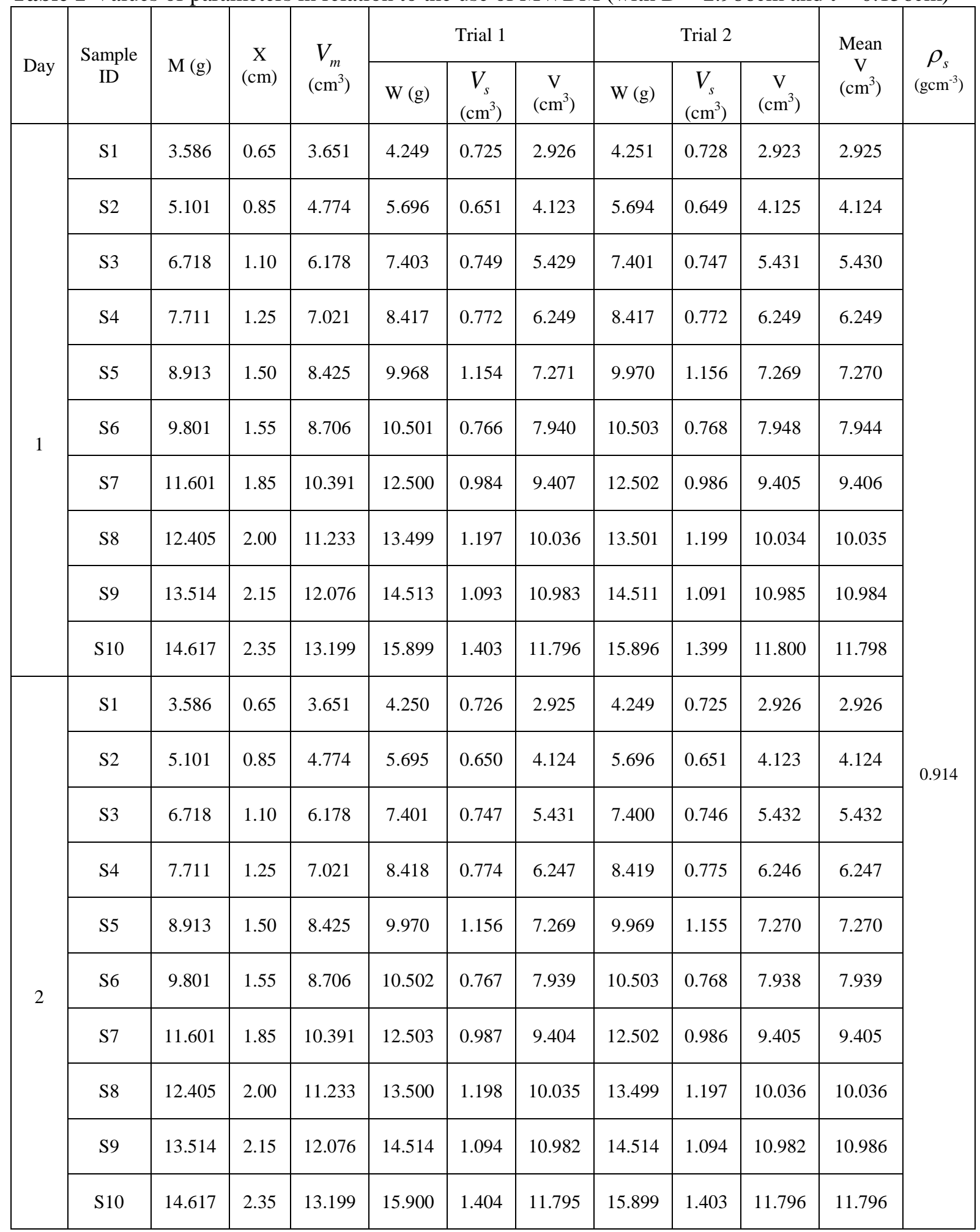

*MWDM = Modified water Displacement Method 
Table 2-Measured volumes of the coated samples by OFM, WDM and SBM

\begin{tabular}{|c|c|c|c|c|c|c|}
\hline \multirow{2}{*}{ Sample ID } & \multirow{2}{*}{$\mathrm{M}(\mathrm{g})$} & \multirow{2}{*}{$\mathrm{W}(\mathrm{g})$} & $V_{s}\left(\mathrm{~cm}^{3}\right)$ & \multicolumn{3}{|c|}{ Mean values of $V_{m}\left(\mathrm{in}^{3}\right)$} \\
\cline { 5 - 7 } & & & & OFM & WDM & $\mathrm{SBM}$ \\
\hline $\mathrm{S} 1$ & 3.586 & 4.249 & 0.725 & 2.913 & 3.9 & 3.649 \\
\hline S2 & 5.101 & 5.696 & 0.651 & 4.417 & 5.0 & 4.773 \\
\hline S3 & 6.718 & 7.403 & 0.749 & 6.136 & 6.6 & 6.183 \\
\hline S4 & 7.711 & 8.417 & 0.772 & 7.329 & 7.9 & 7.016 \\
\hline S5 & 8.913 & 9.968 & 1.154 & 8.034 & 8.6 & 8.421 \\
\hline S6 & 9.801 & 10.501 & 0.766 & 8.443 & 9.0 & 8.709 \\
\hline S7 & 11.601 & 12.500 & 0.984 & 10.138 & 11.3 & 10.393 \\
\hline S8 & 12.405 & 13.499 & 1.197 & 11.655 & 12.3 & 11.230 \\
\hline S9 & 13.514 & 14.513 & 1.093 & 12.149 & 13.0 & 12.079 \\
\hline S10 & 14.617 & 15.899 & 1.403 & 14.063 & 13.9 & 13.202 \\
\hline
\end{tabular}

$* \mathrm{OFM}=$ Overflow method, $\mathrm{WDM}=$ Water displacement method (traditional) $\mathrm{SBM}=$ Suspension/Buoyancy method (gold standard used)

Table 3-Method adopted and mean bulk volume of the samples

\begin{tabular}{|c|c|c|c|c|c|c|}
\hline \multirow{2}{*}{$\begin{array}{c}\text { Sample } \\
\text { ID }\end{array}$} & \multirow{2}{*}{ GEM } & OFM & \multirow{2}{*}{ WDM } & \multicolumn{2}{|c|}{ MWDM (mean values) } & \multirow{2}{*}{$\begin{array}{c}\text { SBM (Gold } \\
\text { standard) }\end{array}$} \\
\cline { 5 - 6 } & & & & Day 1 & Day 2 & \\
\hline S1 & 3.637 & 2.188 & 3.175 & 2.925 & 2.926 & 2.924 \\
\hline S2 & 5.314 & 3.766 & 4.349 & 4.124 & 4.124 & 4.122 \\
\hline S3 & 6.767 & 5.387 & 5.851 & 5.430 & 5.432 & 5.434 \\
\hline S4 & 7.679 & 6.467 & 7.128 & 6.249 & 6.247 & 6.244 \\
\hline S5 & 9.101 & 6.880 & 7.446 & 7.270 & 7.270 & 7.267 \\
\hline S6 & 10.886 & 7.677 & 8.234 & 7.944 & 7.939 & 7.943 \\
\hline S7 & 11.588 & 9.154 & 10.316 & 9.406 & 9.405 & 9.409 \\
\hline S8 & 11.852 & 10.458 & 11.103 & 10.035 & 10.036 & 10.033 \\
\hline S9 & 13.508 & 11.056 & 11.907 & 10.984 & 10.986 & 10.986 \\
\hline S10 & 14.376 & 12.660 & 12.497 & 11.798 & 11.796 & 11.799 \\
\hline
\end{tabular}




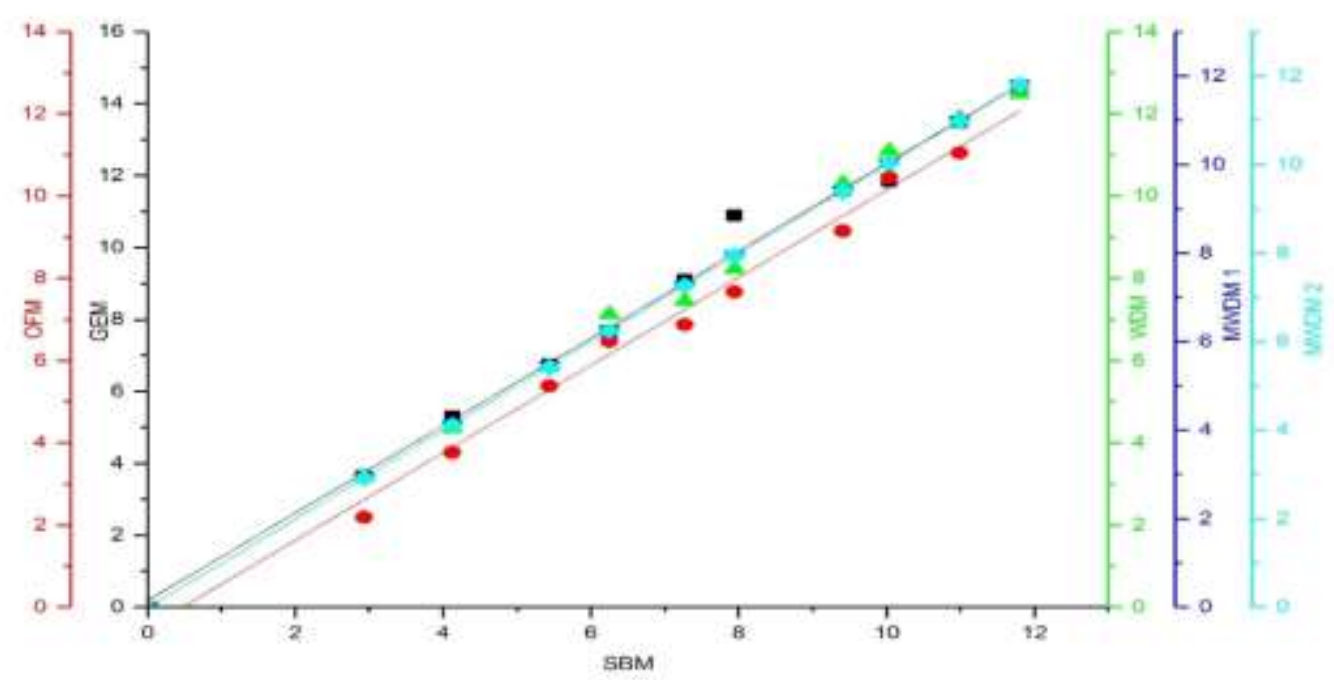

Figure 1-Plots of mean values of measured bulk volume against gold standard values

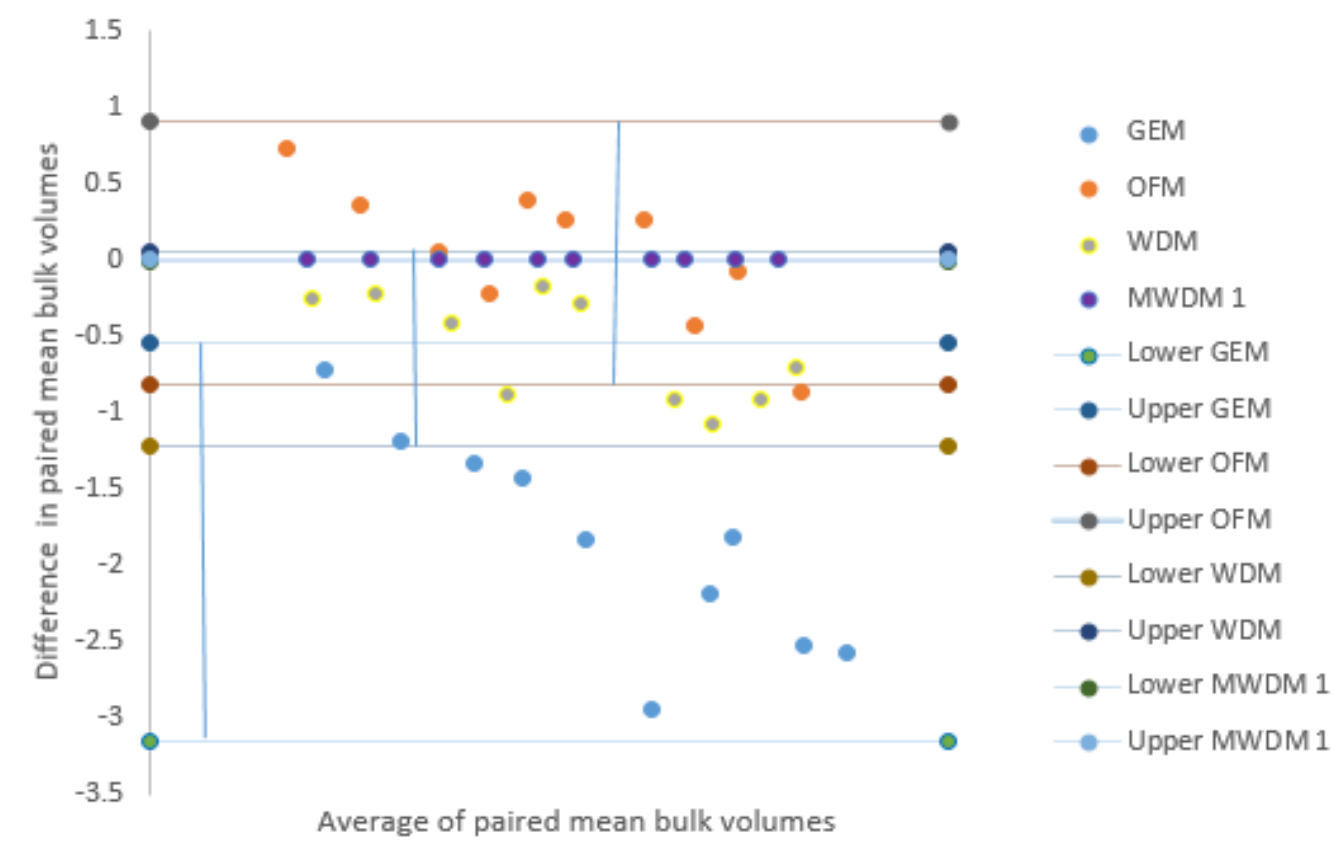

Figure 2-Bland-Altman plots of the difference against average in the mean bulk volumes between other methods and gold standard

\subsection{Discussion}

The experimental data obtained in this work are tabulated in Tables $-1,2$ and 3. It can be seen in Table- 1 that for the two trial runs, the displacement of water remains unchanged though there exists a slight change in the mass of the coated sample in some cases. Similar observation is possible when comparing day 1 data with those obtained on day 2 by the modified water displacement method. This results in reproducibility of $0.03 \%$ which is within the range recommended for acceptability of a test method [12]. Just as it appears in Table- 1 with the use of the MWDM, it can be observed in Table- 2 that the volume of the coated sample increases as the mass of the sample material increases. At 0.05 level of significance, only the data obtained by MWDM yields Pearson's product moment coefficient of 1 when correlated with the gold standard (SBM) data. Though high coefficients are obtained by GEM (0.9939), OFM (0.9955) and WDM (0.9968), the slopes from the plots in Figure- 1 give 44.9950 
and 44.9930 in the case of MWDM data for day 1 and day 2 respectively. But for the GEM, OFM, and WDM, the slope angles are 50.5490, 46.8160 and 47.1390 respectively. Since perfectly agreed and close data only can produce slope angle of 450 in a linear plot, it is obvious that the results obtained by the MWDM are of very high accuracy and precision. By considering this comparison method as advanced by [13], it implies that the data obtained by the MWDM are ideally similar to the gold standard data. This is supported by the narrowest limit of agreement associated with the method as can be observed in the Bland-Altman plot (Figure- 2). While the standard deviation values for GEM, OFM, and WDM in the Bland-Altman analysis are 0.6662, 0.4731 and 0.3276 respectively, the standard deviation value for MWDM (day 1) is 0.0027 . In other words, this plot reveals that though all the methods produce results with high correlation coefficient, it is the MWDM only that yields results with the highest accuracy and insignificant standard deviation values (when considering \pm 1.96 of the obtained standard deviation at 0.05 level of significance).

\section{Conclusion}

It was found that with commonly available laboratory materials, only the modified water displacement method yielded results with correlation coefficient of 1 when tested against the data obtained as gold standard values at 0.05 level of significance. Also, from the Bland-Altman plot, its data were revealed to be of the highest level of agreement with the standard values. In general, its reproducibility was observed to fall within the range recommended for acceptance and the results obtained by it were of high accuracy, precision and validity.

\section{References}

1. Rashidi, R. 2018. Porous Materials in Building Energy Technologies- A Review of the application, modelling and experiments. Renewable and Sustainable Energy Reviews. Doi:10.1016/j.rser.2018.03.092

2. Gunathilake, T.M.S.U., Ching, Y.C., Ching, K.Y., Chuah, C.H., Abdullah, L.C. 2017. Biomedical and Microbiological Applications of Bio-Based Porous Materials. A Review. Polymers, 9(160): 1 16. Doi:10.3390/polym.9050160. www.mdpi.com/journal/polymers

3. Clyne, T.W., Golosnoy, I.O., Tan, J.C., Markaki, A.E. 2006. Porous Materials for Thermal Management Under Extreme Conditions. Philosophical Transactions of the Royal Society, 364: 125 - 146. Doi:10.1098/rsta.2005.1682.

4. Ndupu, B.N.L., Okeke, P.N., Ladipo, O.A. 2000. Senior Secondary Physics 1, New Edition, p. 9, Longman Nigeria PLC, ISBN 978026074-9.

5. Tuttuh-Adegun, M.R., Adegoke, D.G. 2011. New Further Mathematics Project 1. $5^{\text {th }}$ Revised Edition, pp. 423 - 424. Bounty Press Limited Ibadan, Nigeria. ISBN 9789788429234.

6. Anyakoha, M.W. 2013. New School Physics for Senior Secondary Schools, $4^{\text {th }}$ Edition, p.155 Africana First Publishers PLC. ISBN 9789781757112. www.afpublishersplc.com

7. Karen, G. 2018. How to read a graduated cylinder, Sciencing. Last accessed: October 15, https:sciencing-com/read-graduated-cylinder-4780284.html. 15 October 2018.

8. Ikeobi, I.O., Obioha, N.E., Offurum, R.L.N., Oyedum, N.A., Babalola, E.R.A., Otuka, J.O.E., Shuaibu, M.J. and Alao, E.O. 2011. STAN Physics for Senior Secondary Schools 1, New Edition. pp. $167-168$. HEBN publishers PLC, Ibadan, Nigeria ISBN 9789780814144. http://www.hcbnpublishers.com

9. Smith, S. 2018. Advantages and Disadvantages of Digital Meters vs Analog Meters, Sciencing, Last accessed: March 13, 2018. www.sciencing.com

10. Okeke, P.N., Okeke, F.N. and Akande, S.F. 2011. Senior Secondary Physics. Current Edition.p.94. Macmillan Nigeria Publishers Limited, Lagos and Ibadan. ISBN 0333375718.

11. Lide, D.R. 2005. CRC Handbook of Chemistry and Physics, $85^{\text {th }}$ Edition p. 990 (Section 6-S) CRC press, Boca Raton, FL. http://www.hbcpnetbase.com

12. Automotive Industry Action Group (A.I.A.G). 1990. Measurement System Analysis (MSA) Manual, 1st Edition. P.46.

13. Kelly, G. E. 1987. Author's reply to Altman and Bland, Applied statistics. 36: 225 - 227 